\section{References}

${ }^{1}$ Greene, S B, et al, fournal of Chronic Diseases, 1977, 30, 401.

2 Kannel, W B, et al, Annals of Internal Medicine, 1967, 67, 48.

${ }^{3}$ Ballantyne, D, Devine, B L, and Fife, R, British Medical fournal, 1978, 1,880 .

${ }^{4}$ Paetkau, M E, et al, Diabetes, 1977, 26, 46.

5 Isles, C, et al, British Medical fournal, 1979, 1, 579

${ }^{6}$ Office of Population Censuses and Surveys, General Household Survey, 1975. London, HMSO, 1978.

7 West, K M, and Stober, J A, Lancet, 1978, 2, 49.
${ }^{8}$ Astrup, P, and Kjeldsen, K, Medical Clinics of North America, 1974, 58, 323.

9 Hawkins, R L, Nature, 1972, 236, 450.

10 Pichon, $\mathrm{P}$, et al, Bulletin des Sociétés d'Ophtalmologie de France, 1976, 76, 675.

11 Cellina, G U, et al, American Heart fournal, 1975, 89, 18.

12 Pickering, G, in High Blood Pressure, 2nd edn, p 451. London, Churchill, 1968.

(Accepted 29 December 1978)

\title{
Study of special-care baby services in North-west Thames region
}

\author{
JANE VAIZEY, THOMAS E OPPÉ
}

British Medical fournal, 1979, 1, 583-585

\section{Summary and conclusions}

During three months in 1975 admissions to 17 of the 21 special-care baby units in the North-west Thames region were analysed by birth weight and category of care. Of the 1718 babies admitted, one-third needed only observation. Neonatal intensive care formed only a small proportion of the work load in most units. Considerable variation in the pattern of admissions was found. There was some evidence of concentration, about 100 babies being transferred for urgent medical or surgical reasons, and the work load of one unit suggested that it was serving as a referral centre.

It is concluded that the quality of care given to some infants needing intensive care might be improved by greater concentration, and that some units should review their admission policies in order to prevent unnecessary postpartum separation of mother and baby.

\section{Introduction}

There is good evidence in Britain ${ }^{1-3}$ of the beneficial effect of modern intensive neonatal care in improving the prognosis of infants of very low birth weight and those suffering from other serious conditions, but little information is available on the overall work load in special-care baby units (SCBUs). In 1974 the provision of special-care baby cots in England was 36/100 000 population aged 0-14 years, but this ranged between areas from seven to $99 .{ }^{4}$ Nationally ${ }^{4}$ about $15 \%$ of all live-born infants are admitted to SCBUs, but little is known about the reasons for admission or the type of care given. Alberman et al ${ }^{6}$ reported the results of one-day censuses in three Thames health regions and showed that although there appeared to be some overall overprovision of cots, many SCBUs were smaller than recommended by the Expert Group on Special Care for Babies ${ }^{7}$ and had deficiencies of equipment and staffing. Alberman et al acknowledged the limitations of the "cross-sectional" approach in estimating work load, and we have attempted to overcome

St Mary's Hospital Medical School, London W2 1PG JANE VAIZEY, BM, MRCP, honorary senior paediatric registrar THOMAS E OPPÉ, MB, FRCP, professor of paediatrics these by surveying all admissions to SCBUs in one Thames health region over three months. Since the one-day census reported was performed while our study was in progress, the data presented here are additional and complementary to those given for the North-west Thames health authority by Alberman et al.

\section{Method}

Each of the 21 SCBUs in the North-west Thames region was asked to complete a form on every baby admitted during January to March 1975. Information included birth weight, length of stay, reason for admission, reason for transfer (if applicable), investigations performed, and treatment given. The number of forms returned each month was compared with the number of recorded admissions. Twenty units agreed to participate, and 17 returned completed forms on $89 \%$ or more of admissions. We classified infants by birth weightnamely, normal $(>2500 \mathrm{~g})$, low $(1501-2500 \mathrm{~g})$, and very low $(\leqslant 1500 \mathrm{~g})$ and type of care given-namely, transitional, special, and intensive.

Transitional care-We included in this category babies who fulfilled all the following criteria: $(a)$ were admitted at birth for observation; (b) had a birth weight exceeding $2500 \mathrm{~g}$; (c) stayed in the unit for three days or less; and $(d)$ had no special investigations or treatment.

Special care-This group comprised babies not included in the transitional or intensive care category.

Intensive care-Babies in this category fulfilled one or more of the following criteria: (a) had a birth weight of $1250 \mathrm{~g}$ or less; (b) were transferred to another SCBU or hospital for medical or surgical treatment; $(c)$ had continuous positive airway pressure (CPAP), mechanical ventilation (IPPV), exchange transfusion, or surgery; or (d) died.

\section{Results}

There were 1718 admissions (including transfers from other SCBUs) to the 17 units. One unit had 36 admissions, 14 had between 50 and 150 admissions, and two had 230 and 280 admissions respectively. The mean proportion of babies admitted to the SCBUs as indicated by the total number of admissions, excluding babies transferred in, related to the total number of live births in the associated maternity departments was $24.7 \%$, ranging from $14 \%$ to $47 \%$ in individual hospitals. Six units admitted $10-20 \%$ of such infants, five units admitted $20-30 \%$, and four units $30-40 \%$; one unit admitted $47 \%$ of its maternity department's live-born infants, and one SCBU had no associated maternity unit, so all of its admissions were "transfers in."

Forms were returned on $1654(96.3 \%)$ of the 1718 babies admitted, and we estimate that this sample constituted $77 \%$ of all admissions to the 21 units. Over two-thirds of the infants were of normal birth weight (table I). 
TABLE I-Birth weights of 1654 infants admitted to 17 SCBUs

\begin{tabular}{|c|c|c|c|}
\hline Birth weight (g) & $\begin{array}{c}\text { No } \\
\text { admitted }\end{array}$ & $\begin{array}{c}\% \text { of all } \\
\text { admissions }\end{array}$ & Range ( $\%)$ \\
\hline $\begin{array}{l}>2500 \\
1501-2500 \\
\leqslant 1500\end{array}$ & $\begin{array}{r}1150 \\
415 \\
89\end{array}$ & $\begin{array}{r}69 \cdot 5 \\
25 \cdot 1 \\
5 \cdot 4\end{array}$ & $\begin{array}{r}31 \cdot 2-83 \cdot 8 \\
15 \cdot 6-47 \cdot 9 \\
0-25 \cdot 0\end{array}$ \\
\hline
\end{tabular}

There was some centralisation in the care of the 89 babies with birth weights below $1500 \mathrm{~g}$. Twenty-two of them were in one SCBU, whereas 22 others were distributed among 11 units; the remaining 45 were in the other five SCBUs. Of all 1654 infants, $192(11.6 \%)$ were in the intensive care category (table II). Of these, 41 were in one SCBU, 61 were in nine units, and the remaining 90 were in seven units. A total of 643 infants $(38.9 \%)$ required only transitional care.

TABLE II-Category of care given to the 1654 infants

\begin{tabular}{cccc}
\hline Category of care & $\begin{array}{c}\text { No } \\
\text { admitted }\end{array}$ & $\begin{array}{c}\text { \%of all } \\
\text { admissions }\end{array}$ & Range $(\%)$ \\
\hline Transitional & 643 & $38 \cdot 9$ & $\begin{array}{r}0-66 \cdot 2 \\
\text { Special }\end{array}$ \\
Intensive & 819 & $49 \cdot 5$ & $\begin{array}{r}77 \cdot 1-76 \cdot 7 \\
1.5-46 \cdot 6\end{array}$ \\
\hline
\end{tabular}

"Transfers in" to SCBUs-"Transfers in" is defined as admissions to a unit of babies from outside that hospital. It includes babies born at home or in other hospitals and "transfers back" from other hospitals to which the babies had been transferred out. There were 101 transfers in, of which 82 were for urgent medical reasons (see table III). Nine units had no such transfers, six units had between one and five transfers each, and the remaining two had 35 and 36 transfers in respectively.

TABLE III-Birth weight and outcome of 82 babies transferred in for urgent medical reasons

\begin{tabular}{lcccc}
\hline & \multicolumn{3}{c}{ Birth weight $(\mathrm{g})$} & \multirow{2}{*}{ Total } \\
\cline { 2 - 4 } & $>2500$ & $1501-2500$ & $\leqslant 1500$ & \\
\hline No given special care & 17 & 14 & 2 \\
No given intensive care & $13(4)^{*}$ & $11(4)^{*}$ & $25(19)^{*}$ & 43 \\
\hline
\end{tabular}

*Numbers of deaths given in parentheses.

TABLE IV-Birth weights and outcome of infants transferred out of SCBUs for urgent medical or surgical reasons

\begin{tabular}{|c|c|c|c|c|}
\hline Birth weight (g) & Lived & Died & Not known & Total \\
\hline $\begin{array}{l}>2500 \\
1501-2500 \\
\leqslant 1500\end{array}$ & $\begin{array}{c}\text { Numbers tran } \\
1 \\
5 \\
5\end{array}$ & $\begin{array}{c}\text { to oth } \\
4 \\
3 \\
7\end{array}$ & $C B$ s $_{1}$ & $\begin{array}{r}6 \\
8 \\
12\end{array}$ \\
\hline Total & 11 & 14 & 1 & 26 \\
\hline $\begin{array}{l}\quad \text { Numbers } \\
>2500 \\
1501-2500 \\
\leqslant 1500\end{array}$ & $\begin{array}{r}\text { ansferred for } s \\
11 \\
2\end{array}$ & $\begin{array}{c}\text { l reason } \\
10 \\
1\end{array}$ & $\begin{array}{c}\text { children's hos } \\
4 \\
1\end{array}$ & $\begin{array}{r}25 \\
4\end{array}$ \\
\hline Total & 13 & 11 & 5 & 29 \\
\hline Grand total & 24 & 25 & 6 & $55^{*}$ \\
\hline
\end{tabular}

*Excludes one infant (birth weight $>2500 \mathrm{~g}$ ) transferred to children's ward for terminal care.

One of these two units was the one without an attached maternity department, but the other appeared to be serving as the main intensive care unit in the region, although it was not formally designated as such. Of the 82 babies transferred in for urgent medical reasons, 33 needed special care and 49 intensive care (table III). At least 18 of the 101 babies transferred in were from outside the region.

"Transfers out" of SCBUs-"Transfers out" is defined as discharges from SCBUs to other hospitals. The total number of transfers out for urgent medical or surgical reasons was 56, and for other reasons 13. The urgent transfers out were analysed further (table IV) One baby, whose birth weight exceeded $2500 \mathrm{~g}$, was transferred to a children's ward for terminal care. Two units had no transfers out, 12 had between one and five transfers out, and three had between six and 10 transfers out.

Deaths in SCBUs-The total number of deaths in the 17 units in the three months was 84 . This figure includes deaths of babies transferred in from outside the region, and excludes deaths of babies transferred to hospitals outside the region. An estimated $6 \%$ of all babies admitted to SCBUs died.

\section{Discussion}

In 1975 a typical SCBU in the North-west Thames region contained 10-20 cots, which were not often fully utilised. Only one unit had more than 24 cots. $^{6}$ Over one-third of the work load of the typical units was generated by infants of normal or near-normal birth weight who were admitted for a short stay and received no special medical treatment. Within this overall picture, however, there were considerable variations between units in the proportions of total live-born infants in the associated maternity departments admitted to SCBUs and in the proportions of infants given transitional and special care. These differences were probably associated with admissions policies, numbers of cots available, and levels of staffing as well as with the clinical condition of the patients. We also recognise that our distinctions between transitional, special, and intensive care are somewhat artificial, since there is a continuum of neonatal care rather than division into discrete entities. Nevertheless, in two major respects the pattern of neonatal care disclosed by the survey is not consistent with present-day opinion on the optimal management of the newborn.

The survey confirms that $1-2 \%$ of live-born infants receive intensive care. This is best provided in SCBUs with special staffing and equipment as well as continuous and substantial experience in managing these very small and sick infants. There appears to be a need in the region studied for the development of one or two SCBUs which should take over this function, preferably as part of a planned perinatal service for high-risk pregnancies as well as neonatal care. At the other end of the scale disturbingly large numbers of infants are admitted to some SCBUs apparently for observation. Such an admission almost inevitably disrupts the early mother-child relationship and causes maternal anxiety. The argument that this interference is justified on grounds of safety or convenience is no longer tenable in view of the accumulating evidence about the beneficial effects of close contact between the mother and her infant in the early postpartum period. ${ }^{8-10}$

Resolution of these problems will demand, on the one hand, that well-planned arrangements are made for transporting infants requiring intensive care, ${ }^{11}$ and, on the other hand, some improvement in the quality of care and neonatal supervision available in the nurseries of maternity units that appear to be too ready to admit infants to the SCBU.

The results of this survey give quantitative information on the numbers of infants who were transported and permit some estimate of the numbers who might have required transport had a more formal system of centralised intensive care been operative. The survey also identifies units in which an undue proportion of the work load is taken up by infants not requiring special or intensive care. We believe that the general pattern of work of SCBUs in the region has not changed greatly since 1975, but in any event the findings are valuable as a baseline from which changes may be evaluated.

The methods used are more time-consuming and entail more co-operation from SCBU staff than does the one-day census described by Alberman et al. ${ }^{6}$ The additional information obtained from study of a defined population over a set period is enough reason for recommending the use of both epidemiological methods. 
We are grateful for the active support of the consultant paediatricians and medical and nursing staff of the SCBUs in the region, without whose co-operation the survey could not have been done.

\section{References}

${ }^{1}$ Drillien, C M, Developmental Medicine and Child Neurology, 1972, 14, 563.

2 Davies, P A, and Tizard, J P M, Developmental Medicine and Child Neurology, 1975, 17, 3 .

${ }^{3}$ Stewart, A L, et al, Archives of Disease in Childhood, 1977, 52, 97.

4 Committee on Child Health Services, Fit for the Future. London, HMSO, 1976. (Court Report.)
${ }^{5}$ Chamberlain, R, et al, British Births 1970, vol 1. London, Heinemann, 1975.

6 Alberman, E, et al, British Medical fournal, 1977, 2, 1045.

7 Expert Group on Special Care for Babies, Department of Health and Social Security, Reports on Public Health and Medical Subjects, No 127. London, HMSO, 1971.

${ }^{8}$ Oppé, T E, Cerebral Palsy Bulletin, 1960, 2, 233.

9 Klaus, M H, et al, New England fournal of Medicine, 1972, 286, 460.

${ }^{10}$ Brimblecombe, F S W, Richards, M P M, and Roberton, N R C, Separation and Special Care Baby Units. Clinics in Developmental Medicine, no 68. London, Heinemann Medical Books, 1978.

${ }^{11}$ Blake, A M, et al, British Medical fournal, 1977, 4, 13.

(Accepted 28 December 1978)

\title{
Datura intoxication in West Cornwall
}

\author{
PATRICK A BELTON, DAVID O GIBBONS
}

British Medical fournal, 1979, 1, 585-586

Recent reports in the local ${ }^{1}$ and national press and on radio and television have highlighted the abuse of certain datura trees growing in West Cornwall. The species are of South American origin and include Datura sanguinea (figure), D cornigera, and D aurea.

The Solanum family, to which the genus Datura belongs, includes a great number of plants conspicuous for their hypnotic properties, among them the mandrake (Mandragora officinarum), deadly nightshade (Atropa belladonna), and henbane (Hyoscyamus niger). These plants have been used from antiquity as intoxicants and medicines and contain various alkaloids of the tropane configuration. A remarkable feature about them has been the independent discovery in remote parts of the world of their hallucinogenic effects, which have been attributed to magic or supernatural agencies and have caused them to be regarded with dread. Scarcely less striking has been the independent use of distinct species in both the Old World and the New in religious ceremonies, especially in oracular divination, the discovery of hidden objects, and foretelling future events.

Some of the most unusual members of the genus Datura are found in the Andean highlands and adjacent areas. All belong to the subgenus Brugmansia and are arborescent with trumpets of white, yellow, or sanguine flowers hanging in abundance among the branches. They have pendulous indehiscent fruit, which contrasts in form with the erect four-valved capsule of the thorn apple ( $D$ strammonium).

It was ancient practice among the Chibcha Indians of Colombia to administer $D$ aurea to wives and slaves of a departed husband or master and then bury them alive with the deceased. The priests of the Temple of the Sun at Sogamoso used $D$ sanguinea to prepare a local drink known as tonga, which, when ingested, was thought to bring them into communication with the spirits of their forefathers. Several other bizarre practices still remain.

In the mild climate of Cornwall these tree daturas flourish as ornamental shrubs. Misuse of them has been widespread and we report the clinical features of six cases that required admission to hospital.

West Cornwall Hospital, Penzance TR18 2PF

PATRICK A BELTON, MB, MRCPI, senior house officer in medicine DAVID O GIBBONS, MB, MRCP, consultant physician

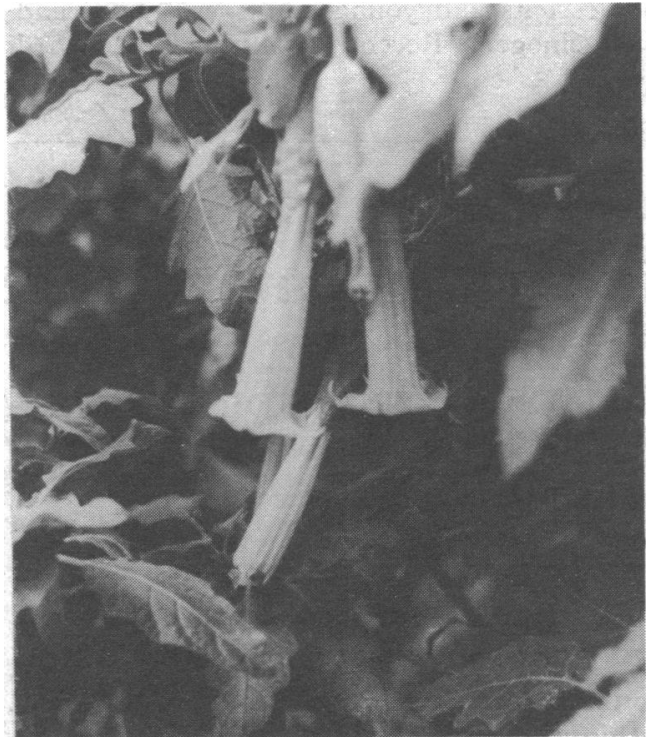

The intoxicating tonga plant, Datura sanguinea.

\section{Case histories}

Five people, aged from 17 to 34 years, had eaten the leaves, while the sixth, a 17-year-old girl, had used them to brew a tea. Four of the cases had imbibed unknown quantities of alcohol first and four had a history of drug abuse. The main clinical features on admission are shown in the table.

The visual hallucinations were apparently without vivid colours or geometric distortion, and objects seen included spiders, trees, and snowdrifts. A particular feature was the tendency to pick imaginary objects from the bedclothes and surrounding curtains. Treatment of the poisoning consisted of gastric lavage and sedation with intramuscular or intravenous diazepam. All cases recovered within 36 hours.

\section{Discussion}

The principal alkaloids contained in the tree daturas are atropine, hyoscine, and hyoscyamine with hyoscine predominating. Other species contain these alkaloids in different proportions. Initial treatment of poisoning is gastric lavage. Delirium and coma can be reversed with physostigmine 